\title{
Do microdeletions lead to immune deficiency?
}

\author{
SAIT KARAMAN ${ }^{l}$, FILIZ HAZAN ${ }^{2}$, SEMIHA BAHÇECI ERDEM ${ }^{l}$, NESRIN GÜLEZI ${ }^{1}$ FERAH GENEL \\ 'Department of Pediatric Allergy and Immunology, Dr Behçet Uz Children's Hospital, Izmir, Turkey \\ ${ }^{2}$ Department of Medical Genetics, Dr Behcet Uz Children's Hospital, Izmir, Turkey
}

\begin{abstract}
Introduction: Microdeletion syndromes may be accompanied by immunological disorders. This study aimed to evaluate the clinical and laboratory data as well as the immune functions of patients diagnosed with a microdeletion syndrome.

Material and methods: 39 patients diagnosed with microdeletion syndrome who were monitored at the Pediatric Genetics and Immunology clinics at Dr. Behcet Uz Children's Hospital were included in this study. All data for this research were obtained from patient records and by individual consultation with their parents.

Results: Of the 39 patients, 15 were monitored for a diagnosis of Williams syndrome, 12 for DiGeorge syndrome, 4 for Prader-Willi syndrome, 2 for Wolf-Hirschhorn syndrome, 1 for a 1 p36 deletion, 1 for Smith-Magenis syndrome, 2 for Trichorhinophalangeal syndrome type 2 (TRPS2), and 2 for Cri-du-chat syndrome. Of these 39 patients, 10 (25.6\%) had a medical history of frequent upper respiratory tract infections. One of the cases with TRPS2 and another with Smith-Magenis syndrome had previously received intravenous antibiotic therapy for infectious disease. Five of the 12 patients with DiGeorge syndrome had low Tlymphocytes. Two of the patients with DiGeorge syndrome with a history of frequent infections, with hypogammaglobinemia, and low lymphocytes were receiving regular intravenous immunoglobulin (IVIG) replacement.

Conclusions: It must be taken into account that patients with microdeletion syndromes, especially those with DiGeorge syndrome, may also have immunodeficiencies; therefore, these patients should be closely monitored to prevent development of any complications.
\end{abstract}

Key words: children, immunodeficiency, microdeletion.

(Centr Eur J Immunol 2020; 45 (1): 69-72)

\section{Introduction}

Patients with microdeletion syndromes often experience recurrent respiratory tract infections, which are the major cause of their mortality and morbidity. However, immunodeficiency is often not suspected in these patients and immunologic investigation is usually not performed [1]. Identification of underlying immunodeficiencies may not only decrease the morbidity and mortality of these patients, but also it may increase their quality of life [2]. Many genetic causes of primary immunodeficiencies have been identified. Well-defined immunodeficiencies (regarding the number and structure of chromosomes) are categorized separately for the classification of primary immunodeficiency $[3,4]$. Previous studies reveal that Down syndrome cases have high rates of immunodeficiency; however, immunodeficiency has not been studied in many other types of microdeletion syndromes. Indeed, immunodeficiency screening has not been reported in cases with dysmorphic findings other than those with Down syndrome [5].
In the current study, we aimed to evaluate the clinical and laboratory data as well as the immunological functions of patients who were monitored for the diagnosis of microdeletion syndrome.

\section{Material and methods}

In this study, 39 patients were included who were diagnosed with microdeletion syndrome in the Pediatric Genetics and Immunology polyclinics of Dr. Behçet Uz Pediatric Diseases and Surgery Training and Research Hospital. The data for this study were obtained from patient records and by individually interviewing their parents. This study was conducted in accordance with the guidelines of the ethics committee of the Dr. Behçet Uz Pediatric Diseases and Surgery Training and Research Hospital (decision dated May 26, 2016, protocol number 2016/79, decision approval 2016/08).

The following data were collected for this study: age, gender, diagnosis, parental consanguinity, history of fre-

Correspondence: Sait Karaman, MD, Department of Pediatric Allergy and Immunology, Dr. Behçet Uz Children's Hospital, Izmir, Turkey, e-mail: saitkaraman73@gmail.com

Submitted: 17.02.2018; Accepted: 07.11.2018 
quent upper respiratory tract infection, antibiotic prophylaxis intake, immunoglobulin replacement, and immunological laboratory data.

The complete blood counts of peripheral blood samples taken in EDTA tubes were performed using the Mindray BC-6800. Serum immunoglobulin (Ig) levels and IgG subgroups were analyzed via nephelometric method (Dade Behring Marburg Gmbh, Germany), and the results were compared with normal levels in terms of age [6]. Serum anti-tetanus and anti-HBs levels were analyzed with commercial Elisa kits. Anti-HBs levels higher than $10 \mathrm{mIU} / \mathrm{ml}$ and anti-tetanus levels of equal to or higher than $0.01 \mathrm{IU} / \mathrm{ml}$ indicated immunity. A peripheral lymphocyte subgroup analysis was performed with a five-color flow cytometry device (Beckman Coulter, Cytomics FC 500); CD45 FITC, CD14 PE, CD3 FITC, CD4 FITC, CD8 PE, CD19 PE, CD16-56 PE, and HLADR-PE monoclonal antibodies were used. Total lymphocyte counts, cell percentages (for CD3+T lymphocyte, CD4+T lymphocyte, CD8+T lymphocyte, CD19+B lymphocyte, and CD3$16+56+\mathrm{NK})$, and the absolute counts of these cells were compared with normal values in terms of age [7].

\section{Statistical analysis}

An SPSS 22.0 (IBM Corporation, Armonk, New York, United States) program was used to analyze the data. The Shapiro-Wilk test was applied to determine whether the data was normally distributed, and the Levene's test was used to determine the variance of homogeneity. Quantitative variables were expressed as mean $\pm \mathrm{SD}$ (standard deviation) and median range (maximum-minimum), while the categorical variables were expressed as $n(\%)$.

Table 1. Characteristics of cases in the study

\begin{tabular}{ll}
\hline Characteristic & Value \\
\hline Gender (male), $\%$ & 51.2 \\
\hline Age, years ${ }^{*}$ & 5 \\
\hline Presence of parental consanguinity, $\%$ & 12.8 \\
\hline $\begin{array}{l}\text { History of having frequent respiratory tract } \\
\text { infections, } \%\end{array}$ & 25.6 \\
\hline Williams syndrome, $n$ & 15 \\
\hline DiGeorge syndrome, $n$ & 12 \\
\hline Prader-Willi syndrome, $n$ & 4 \\
\hline Wolf-Hirschhorn syndrome, $n$ & 2 \\
\hline 1p36 deletion, $n$ & 1 \\
\hline Smith-Magenis syndrome, $n$ & 1 \\
\hline TRPS2, $n$ & 2 \\
\hline Cri-du-chat syndrome, $n$ & 2 \\
\hline${ }^{*}$ medium & \\
\hline
\end{tabular}

\section{Results}

Twenty of the 39 cases $(51.2 \%)$ were male, and their age ranged from 6 months to 16 years (median, 5 years). Fifteen of these cases were monitored for a diagnosis of Williams syndrome, 12 for DiGeorge syndrome, 4 for Prader-Willi syndrome, 2 for Wolf-Hirschhorn syndrome, 1 for a 1p36 deletion, 1 for Smith-Magenis syndrome, 2 for Trichorhinophalangeal syndrome type 2 (TRPS2), and 2 for Cri-du-chat syndrome. Five of the 39 cases (12.8\%) had parental consanguinity. Two cases had the ten signs of Jeffrey modell foundation's immunodeficiency. Two patients (one with TRPS2 and one with Smith-Magenis syndrome) had a history of intravenous antibiotic treatment for pneumonia. Ten of the 39 cases $(25.6 \%)$ had a history of frequent upper respiratory tract infections. Three of these were diagnosed with Williams syndrome, one with TRPS2 syndrome, four with DiGeorge syndrome, one with WolfHirschhorn syndrome, and one patient with Smith-Magenis syndrome (Table 1). None of these cases underwent antibiotic prophylaxis. T-lymphopenia was detected in five cases with DiGeorge syndrome. Two patients with DiGeorge syndrome had frequent upper respiratory tract infection, hypogammaglobinemia, and low T lymphocytes; they were receiving regular intravenous immunoglobulin (IVIG) replacement. In addition, autoimmune thrombocytopenia and hemolytic anemia were observed in one of these two cases. In terms of age, all of the other patients had normal levels of IgA, M, G, and IgE, IgG subgroup (IgG1, G2, G3, and IgG4), complement (C3 and C4), leukocyte counts, lymphocyte counts, and lymphocyte subgroups [CD3, CD4, CD8, CD19, natural killer cells (NK), CD4/CD8, CD3 HLADR] (Table 2). There was no response to hepatitis $B$ vaccine in seven of the Williams syndrome cases $(46 \%)$ and four of the Prader-Willi syndrome cases $(100 \%)$. Tetanus vaccine response was negative in two cases with the Prader-Willi syndrome. After one dose of hepatitis B vaccine, anti-Hbs antibody was positive in four of seven cases with the Williams syndrome and in two of the four cases with PraderWilli syndrome. After these cases received the hepatitis B and tetanus vaccines, the values of anti-Hbs and anti-tetanus antibodies became positive in all of the patients.

\section{Discussion}

Several studies have reported on immunodeficiency in patients with DiGeorge syndrome [8, 9]. However, studies reporting on immunodeficiencies in other microdeletion syndromes are limited to case reports. In our current study, immune functions in DiGeorge syndrome were analyzed as well as in seven other microdeletion syndromes. Our data does not support testing for immune deficiencies in microdeletion syndromes other than DiGeorge syndrome.

The study of Schatorjé et al. evaluated the immunological functions of patients with chromosomal anomalies and 
frequent infections, and found that one third of the cases had a primary immunodeficiency [10]. In our study, four cases with DiGeorge syndrome had immunodeficiency and a history of frequent upper respiratory tract infections; however, no immunodeficiency was detected in the other six microdeletion syndrome cases with a history of frequent upper respiratory tract infection. Upper airway infections may (most likely) have other causes in these patients such as smoke, crowded family life, and nursery.

First, Kabuki et al. reported chronic granulomatous disease in a 2-month-old Williams syndrome patient [11]. Later, Stasia et al. reported that they also detected chronic granulomatous disease in two patients with the Williams syndrome [12]. In our current study, none of the patients with Williams syndrome had a history of infection suggesting chronic granulomatous disease. In addition, all of these patients had normal levels of immune function.

In a study including patients with Wolf-Hirschhorn syndrome, Hanley-Lopez et al. reported that common variable immunodeficiency was detected in two cases, with one patient diagnosed with $\operatorname{IgA}$ and $\operatorname{IgG} 2$ subclass deficiency, three identified with IgA deficiency, and three diagnosed with insufficient polysaccharide vaccine response [13]. Campos-Sanchez et al. reported that the genes involved in the genetic deletion leading to Wolf-Hirschhorn syndrome, play a key role in the proliferation of B cells [14]. However, despite the fact that one of our two patients with Wolf-Hirschhorn syndrome had a history of frequent upper respiratory tract infection, the Ig and IgG subgroup levels in both of these patients were normal in terms of their age as well as their other immunological parameters.

Suhoski et al. reported that the genes undergoing deletion by 1 p36 microdeletion encode the costimulatory molecules of the TNF receptor superfamily (TNFRSF) [15]. However, primary immunodeficiency due to $1 \mathrm{p} 36$ deletion has not yet been reported in the literature. In our current study, there were no clinical findings suggesting immunodeficiency, and patients' immunologic parameters were normal.

Perkins T et al. reported that 74 of 76 patients with Smith-Magenis syndrome had frequent recurrent infections such as otitis, pneumonia, sinusitis, and gastroenteritis. In addition, most of the patients with Smith-Magenis syndrome had deficient isotype-switched memory B cells [16]. In our study, the patients with Smith Magenis syndrome had a history of recurrent upper respiratory tract infection (consistent with the literature) and a history of pneumonia requiring intravenous antibiotic treatment. However, the Ig levels and IgG subgroup levels of these patients were normal in terms of their age. While B lymphocyte subgroups were not investigated, their B lymphocyte count, its ratio, and other laboratory data were within normal range.

It has been reported that while less than $1 \%$ of cases with DiGeorge syndrome have severe combined immunodeficiency [17], 75\% of them have inadequate immunological functions at different levels [18]. Many retrospective

\begin{tabular}{|c|c|c|c|c|}
\hline 气ิ & $\begin{array}{ll}\infty & n \\
0 & n \\
0 & 0 \\
+1\end{array}$ & $\stackrel{\infty}{\stackrel{\bar{I}}{+1}}$ & $-n$ & ت $\stackrel{\infty}{+}$ \\
\hline z & $\begin{array}{rl}- & 0 \\
0 & 0 \\
0 & 0 \\
+1\end{array}$ & $\begin{array}{ll}\infty & t \\
& \sigma\end{array}$ & $\pm \stackrel{n}{=}$ & $\begin{array}{ll}\infty & \sigma \\
\ddot{n} & \vec{n} \\
+1\end{array}$ \\
\hline อิ & $\begin{array}{ll}\circ & \infty \\
\infty & \infty \\
\stackrel{+}{+}\end{array}$ & $\stackrel{0}{\stackrel{i}{i}}$ & $\simeq \simeq$ & 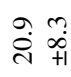 \\
\hline 己ิ & 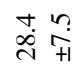 & 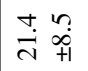 & $\bar{\sim}$ तิ & $\begin{array}{l}0 \\
\dot{+} \\
\stackrel{0}{0}\end{array}$ \\
\hline ปิ & $\hat{\dot{q}} \hat{\dot{\phi}}$ & 递 & $i n$ & 它 \\
\hline ชิ & $\overrightarrow{\mathrm{i}}$ & $\begin{array}{l}0 \\
\stackrel{0}{ \pm}\end{array}$ & $\approx \hat{\sigma}$ & $\begin{array}{l}n \\
n \\
j \\
0 \\
0 \\
+1\end{array}$ \\
\hline$\stackrel{3}{3}$ & $\begin{array}{l}\stackrel{0}{0} \\
\bar{m} \\
\frac{n}{+1}\end{array}$ & 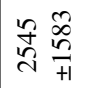 & $\frac{8}{\pi} \frac{\pi}{m}$ & 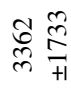 \\
\hline$\widehat{\underline{B}}$ & 号 & 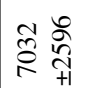 & 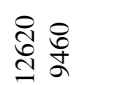 & 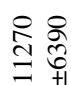 \\
\hline ठ & 宅 & $\stackrel{\infty}{\stackrel{m}{\sim}} \stackrel{m}{+1}$ & ㄴ & 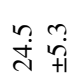 \\
\hline 己 & \begin{tabular}{l}
$n$ \\
$\stackrel{0}{0}$ \\
$\varrho$ \\
\hdashline
\end{tabular} & 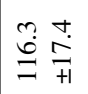 & $\hat{\Sigma} \hat{\Omega}$ & $\begin{array}{l}n \\
\infty \\
\infty \\
\infty\end{array}$ \\
\hline 节 & 它京 & $-\frac{\hat{r}}{\infty}$ & $\curvearrowright \stackrel{\infty}{\infty}$ & \begin{tabular}{l}
$\sim$ \\
$\sim$ \\
\multirow{\gamma}{*}{$\underset{+}{0}$} \\
+1
\end{tabular} \\
\hline 乌ુ & 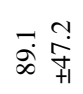 & 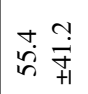 & $\stackrel{\cong}{\cong}$ & 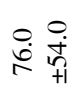 \\
\hline 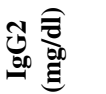 & 芦 & 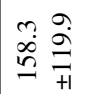 & 方 导 & $\stackrel{m}{\stackrel{m}{\sim}} \frac{r}{+1}$ \\
\hline & 年 & 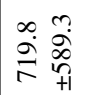 & $\stackrel{\circ}{n}$ & $\overrightarrow{\frac{1}{8}} \frac{\stackrel{m}{7}}{+1}$ \\
\hline 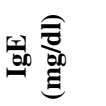 & 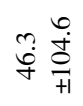 & $\begin{array}{ll}\infty & 0 \\
\ddot{m} & \stackrel{\vec{H}}{+1}\end{array}$ & 구 $\infty$ & $\stackrel{?}{a} \frac{?}{\equiv}$ \\
\hline$\sum_{00} \overline{\bar{\theta}}$ & 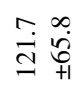 & 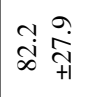 & $\stackrel{\infty}{\infty} \stackrel{\varrho}{=}$ & 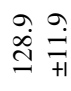 \\
\hline 彔 & 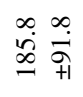 & 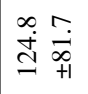 & 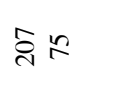 & 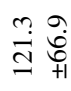 \\
\hline & 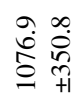 & 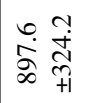 & 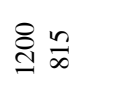 & 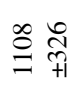 \\
\hline שֶ. & 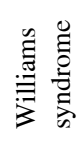 & 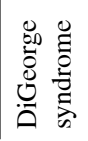 & 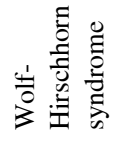 & 总 \\
\hline
\end{tabular}


studies have reported that cases with DiGeorge syndrome had an increased incidence of autoimmune diseases; these studies further reveal that approximately $10 \%$ of these patients developed autoimmunity [19, 20]. In European and United States registries, approximately 3\% of DiGeorge syndrome cases have been reported to receive immunoglobulin replacement [21]. In our current study, none of the cases with DiGeorge syndrome had severe combined immunodeficiency. In accordance with the literature, four of the twelve DiGeorge syndrome patients had frequent recurrent upper respiratory tract infections, and lymphopenia was detected in five cases. Only two DiGeorge syndrome cases received regular IVIG replacement, since they had frequent respiratory tract infections, hypogammaglobinemia, and lymphopenia. In addition, one of these two cases also had autoimmunity.

In the literature, to our knowledge, there are no studies reporting primary immunodeficiency in Prader-Willi syndrome, TRPS2, and Cri-du-chat syndromes. In our study, one case with the diagnosis of TRPS2 had a history of frequent upper respiratory tract infections. Of note, this case had previously received intravenous antibiotic treatment for pneumonia. However, we did not detect immunodeficiency in any of these three syndromes.

There was no response to hepatitis B vaccine in the Williams syndrome cases (46\%) and in the Prader-Willi syndrome cases (100\%) in our study. Additionally, there was no response to tetanus vaccine in the Prader-Willi syndrome patients $(50 \%)$. After these cases received the hepatitis B and tetanus vaccines, the values of anti-Hbs and anti-tetanus antibodies became positive in all of patients. To our knowledge, there is no study in the literature on vaccine responses in these syndromes, so greater study on vaccine responses of these syndromes are essential.

\section{Conclusions}

In conclusion, in accordance with the literature, the current study found that primary immunodeficiencies were frequent in DiGeorge syndrome cases. Immunodeficiency was not detected in any other of the microdeletion syndromes. However, as reported in the literature, the evaluation of immunodeficiency in microdeletion syndromes, especially Wolf-Hirschhorn syndrome, 1 p36 microdeletion, and Smith-Magenis syndrome, may increase the quality of life of patients by preventing complications that may otherwise develop.

\section{The authors declare no conflict of interest.}

\section{References}

1. Shima H, Kitagawa H, Wakisaka M, et al. (2010): The usefulness of laryngotracheal separation in the treatment of severe motor and intellectual disabilities. Pediatr Surg Int 26: 1041-1044.

2. Quinti I, Soresina A, Guerra A, et al. (2011): Effectiveness of immunoglobulin replacement therapy on clinical outcome in patients with primary antibody deficiencies: results from a multicenter prospective cohort study. J Clin Immunol 31: 315-322.

3. Seidel MG, Duerr C, Woutsas S, et al. (2014): A novel immunodeficiency syndrome associated with partial trisomy $19 \mathrm{p} 13$. J Med Genet 51: 254-263.

4. Seppanen M, Koillinen H, Mustjoki S, et al. (2014): Terminal deletion of $11 \mathrm{q}$ with significant late-onset combined immune deficiency. J Clin Immunol 34: 14-18.

5. Mahmoud SA, Lowery-Nordberg M, Chen H, et al. (2005): Immune defects in subjects with dysmorphic disorders. Allergy Asthma Proc 26: 373-381.

6. Aksu G, Genel F, Koturoglu G, et al. (2006): Serum immunoglobulin (IgG, IgM, IgA) and IgG subclass concentrations in healthy children: a study using nephelometric technique. Turk J Pediatr 48: 19-24.

7. Tosato F, Bucciol G, Pantano G, et al. (2015): Lymphocytes subsets reference values in childhood. Cytometry A 87: 81-85.

8. Kusters MA, Verstegen RH, Gemen EF, de Vries E (2009): Intrinsic defect of the immune system in children with down syndrome: a review. Clin Exp Immunol 156: 189-193.

9. Davies EG (2013): Immunodeficiency in DiGeorge syndrome and options for treating cases with complete athymia. Front Immunol 4: 322.

10. Schatorjé E, van der Flier M, Seppänen M, et al. (2016): Primary immunodeficiency associated with chromosomal aberration - an ESID survey. Orphanet J Rare Dis 11: 110.

11. Kabuki T, Kawai T, Kin Y, et al. (2003): A case of Williams syndrome with p47-phox-deficient chronic granulomatous disease. Nihon Rinsho Meneki Gakkai Kaishi 26: 299-303.

12. Stasia MJ, Mollin M, Martel C, et al. (2013): Functional and genetic characterization of two extremely rare cases of Williams-Beuren syndrome associated with chronic granulomatous disease. Eur J Hum Genet 21: 1079-1084.

13. Hanley-Lopez J, Estabrooks LL, Stiehm R (1998): Antibody deficiency in Wolf-Hirschhorn syndrome. J Pediatr 133: 141-143.

14. Campos-Sanchez E, Deleyto-Seldas N, Dominguez V, et al. (2017): Wolf-Hirschhorn Syndrome Candidate 1 Is Necessary for Correct Hematopoietic and B Cell Development. Cell Rep 19: 1586-1601.

15. Suhoski MM, Perez EE, Heltzer ML, et al. (2008): Monosomy $1 \mathrm{p} 36$ uncovers a role for OX40 in survival of activated CD4+ T cells. Clin Immunol 128: 181-189.

16. Perkins T, Rosenberg JM, Le Coz C, et al. (2017) Smith-Magenis Syndrome Patients Often Display Antibody Deficiency but Not Other Immune Pathologies. J Allergy Clin Immunol Pract 5: 1344-1350.

17. Markert ML, Devlin BH, Alexieff MJ, et al. (2007): Review of 54 patients with complete DiGeorge anomaly enrolled in protocols for thymus transplantation: outcome of 44 consecutive transplants. Blood 109: 4539.

18. McDonald-McGinn DM, Sullivan KE (2011): Chromosome 22q11.2 deletion syndrome (DiGeorge syndrome/velocardiofacial syndrome). Medicine (Baltimore) 90: 1.

19. Tison BE, Nicholas SK, Abramson SL, et al. (2011): Autoimmunity in a cohort of 130 pediatric patients with partial DiGeorge syndrome. J Allergy Clin Immunol 128: 1115.

20. Cancrini C, Puliafito P, Digilio MC, et al. (2014): Clinical features and follow-up in patients with 22 q11.2 deletion syndrome. J Pediatr 164: 1475.

21. Patel K, Akhter J, Kobrynski L, et al. (2012): Immunoglobulin deficiencies: the B-lymphocyte side of DiGeorge Syndrome. J Pediatr 161: 950. 